\title{
Nuclear Magnetic Resonance in Hexaferrite/Maghemite Composite Nanoparticles
}

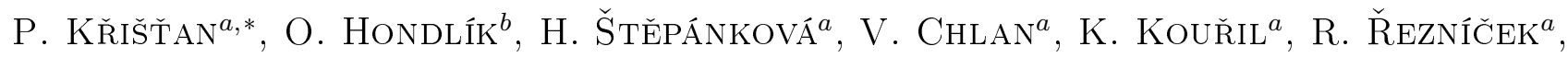 \\ E. POLlerT ${ }^{c}$ AND P. VEVERKA ${ }^{c}$ \\ ${ }^{a}$ Charles University in Prague, Faculty of Mathematics and Physics, \\ V Holešovičkách 2, 18000 Prague 8, Czech Republic \\ ${ }^{b}$ Faculty of Biomedical Engineering, Czech Technical University in Prague, \\ Sítná sq. 3105, 27201 Kladno, Czech Republic \\ 'cInstitute of Physics, ASCR, Cukrovarnická 10, 16253 Prague 6, Czech Republic
}

\begin{abstract}
Due to their bio-compatibility and non-toxicity, ferrimagnetic iron oxides are suitable for various medical applications. In the case of hyperthermia, the promising approach how to reach desired magnetic properties is to combine more phases into a composite material. A series of samples containing maghemite and M-hexaferrite was prepared by sol-gel method with subsequent thermal treatment where annealing temperature and time were varied. The samples were characterized by X-ray diffraction. In this paper we focused mainly on application of nuclear magnetic resonance spectroscopy to investigate these strongly inhomogeneous nanoparticle composites. Frequencyswept ${ }^{57}$ Fe NMR spectra of nanoparticle samples were measured in a zero external magnetic field at $4.2 \mathrm{~K}$. Utilizing differences in optimal excitation field strengths and in relaxation times, we were able to resolve NMR signal assigned to hexagonal ferrite of M-phase from signal which showed features attributed to maghemite.
\end{abstract}

DOI: 10.12693 /APhysPolA.127.514

PACS: 76.60.-k, 75.50.Gg, 75.50.Tt, 75.47.Lx, 61.66.Fn

\section{Introduction}

Magnetic iron oxide particles of submicron and nanoscale dimensions are employed as functional materials in a variety of technical and biomedical applications. The composition of nowadays used biologically harmless ferrimagnetic oxide materials is based on maghemite $(\gamma$ $\left.\mathrm{Fe}_{2} \mathrm{O}_{3}\right)$ or magnetite $\left(\mathrm{Fe}_{3} \mathrm{O}_{4}\right)$ spinel structure. Their synthesis is relatively simple; their magnetic properties however can be modified only by variation of the particle dimension or structural defects.

To improve the magnetic properties of particles for applications in magnetic fluid hyperthermia, attention is paid to more complex magnetic oxides. Optimization of chemical composition was searched for lanthanum manganese perovskites or $\mathrm{Co}-\mathrm{Zn}$ spinel ferrites [1].

Another approach consists in applying of multiphase composite materials $[1,2]$, where the combined contribution of different magnetic phases makes it possible to appropriately adjust magnetization, coercivity, and remanence and consequently the shape of the hysteresis loop and heating effect due to the energy absorbed from ac magnetic field. In materials combining maghemite and hexaferrite, the pronounced difference in magnetic anisotropies enables to control magnetic properties of the composite mainly by the ratio of the two ferrimagnetic phases.

*corresponding author; e-mail: Petr.Kristan@mff.cuni.cz
${ }^{57} \mathrm{Fe}$ nuclear magnetic resonance (NMR) spectroscopy proved to be successful in microstructure studies of magnetic iron oxides when the resonating ${ }^{57} \mathrm{Fe}$ nuclei serve as a local hyperfine field probe sensitive to atomic and magnetic arrangement in their vicinity $[3,4]$. However, this experimental method has not been systematically applied to investigation of coexistence of two or more different magnetic phases with overlapping spectra.

This paper focuses on series of nanoparticle powder samples containing one or two ferrimagnetic phases, i.e. maghemite $\gamma-\mathrm{Fe}_{2} \mathrm{O}_{3}$ and strontium M-type hexaferrite $\mathrm{SrFe}_{12} \mathrm{O}_{19}$. The sample series was investigated by ${ }^{57} \mathrm{Fe}$ NMR.

\section{Experimental}

Series of nanoparticle samples with variable amount of maghemite and M-hexaferrite phases was prepared via sol-gel method with subsequent thermal treatment where annealing temperature and time were varied (Table). More details about preparation are given in $[5,6]$. Xray diffraction was applied to determine mean crystallite size $d_{X R D}$ and phase composition. Besides maghemite and hexaferrite, hematite $\alpha-\mathrm{Fe}_{2} \mathrm{O}_{3}$ and also $\mathrm{SrCO}_{3}$ were detected.

NMR spectra were recorded at $4.2 \mathrm{~K}$ in zero external magnetic field using Bruker Avance pulse spectrometer. The sample was placed in the coil of a tunable parallel resonant circuit of in-house-made NMR probe. ${ }^{57} \mathrm{Fe}$ NMR frequency-swept spectra with typical frequency step of $50-100 \mathrm{kHz}$ were acquired in a frequency range of $68-77 \mathrm{MHz}$ using multipulse spin echo 
TABLE

Composite nanoparticle samples.

\begin{tabular}{|c|c|c|c|c|c|c|c|}
\hline \multirow{2}{*}{$\begin{array}{l}\text { Sam- } \\
\text { ple }\end{array}$} & \multicolumn{2}{|c|}{ Annealing } & \multirow{2}{*}{\multicolumn{2}{|c|}{$\begin{array}{c}\text { Particle size } \\
d_{X R D}[\mathrm{~nm}]\end{array}$}} & \multicolumn{3}{|c|}{$\begin{array}{c}\text { Composition [\%] } \\
\text { (iron oxide phases) }\end{array}$} \\
\hline & {$\left[\begin{array}{l}\text { Temp } \\
{\left[{ }^{\circ} \mathrm{C}\right]}\end{array}\right.$} & $\left.\begin{array}{l}\text { Time } \\
{[\mathrm{min}]}\end{array}\right]$ & & & Hexaferrite & Maghemite & Hematite \\
\hline $\mathrm{m} 1$ & 550 & 180 & & 9 & 0 & 98.6 & 0 \\
\hline $\mathrm{m} 2$ & 500 & 180 & & 11 & 0 & 96.9 & 0 \\
\hline $\mathrm{mh} 1$ & 600 & 32 & $\begin{array}{c}6 \\
\text { (hex.) }\end{array}$ & $\begin{array}{c}16 \\
\text { (magh.) }\end{array}$ & 6.3 & 79.7 & 3.3 \\
\hline $\mathrm{mh} 2$ & 600 & 67 & $\begin{array}{c}15 \\
\text { (hex.) }\end{array}$ & $\begin{array}{c}14 \\
\text { (magh.) }\end{array}$ & 11.9 & 77.2 & 5.6 \\
\hline $\mathrm{mh} 3$ & 600 & 190 & & 32 & 41.2 & 47.1 & 10.1 \\
\hline h1 & 700 & 22 & & 32 & 78.0 & 0 & 22.0 \\
\hline h2 & 800 & 20 & & 62 & 70.6 & 0 & 29.4 \\
\hline h3 & 800 & 146 & & 81 & 75.1 & 0 & 24.9 \\
\hline
\end{tabular}

Carr-Purcell-Meiboom-Gill (CPMG) pulse sequence. Individual echoes formed in the sequence were summed and Fourier transformed.

In pulse NMR spectroscopy it is necessary to properly adjust amplitude of applied radiofrequency (rf) field pulses to reach optimal excitation of NMR signal. In the case of magnetic materials, the optimal rf field is strongly sample/phase-specific because it depends on rf field enhancement induced by hyperfine coupling of nuclear and electron spins [7]. The enhancement factor is expected to be significantly higher in maghemite than in magnetically hard hexaferrite $\mathrm{SrFe}_{12} \mathrm{O}_{19}$. Dependences of the NMR signal on rf field amplitude were therefore carefully measured for the studied samples. Delay time between pulse sequences and selection of summed spin echoes in CPMG train were other controlled parameters of acquisition and data processing.

\section{Results and discussion}

${ }^{57} \mathrm{Fe}$ NMR spectra measured in a range of $68-77 \mathrm{MHz}$ are shown in Fig. 1. In the dependence of signal intensity on rf field amplitude obtained for samples $\mathrm{m} 1$ and $\mathrm{m} 2$ just one maximum appeared, delay time of tens of ms between scans was sufficient for full spin-lattice relaxation, also spin-spin relaxation was rather fast so that intensities of echo signals in CPMG train decreased considerably but homogeneously within the whole spectral range. Spectra of samples $\mathrm{m} 1$ and $\mathrm{m} 2$ (Fig. 1a) show typical shape corresponding to maghemite phase [8-12].

Also for samples h1, h2, and h3 the dependence of signal on rf field amplitude showed one maximum, this case at relatively stronger rf field, necessary delay time was about $1 \mathrm{~s}$, spin-spin relaxation was significantly slower than for $\mathrm{m} 1$ and $\mathrm{m} 2$. Spectra of all three samples h1-h3 (Fig. 1b) correspond to M-hexaferrite structure $[13,14]$ and are very similar in line positions and widths. In comparison with single crystal of strontium M-hexaferrite, the spectral lines are substantially broadened and shifted from single crystal resonance frequencies (12k: $71.0420 \mathrm{MHz}, 4 \mathrm{f}_{\mathrm{IV}}$ : $72.7210 \mathrm{MHz}$,

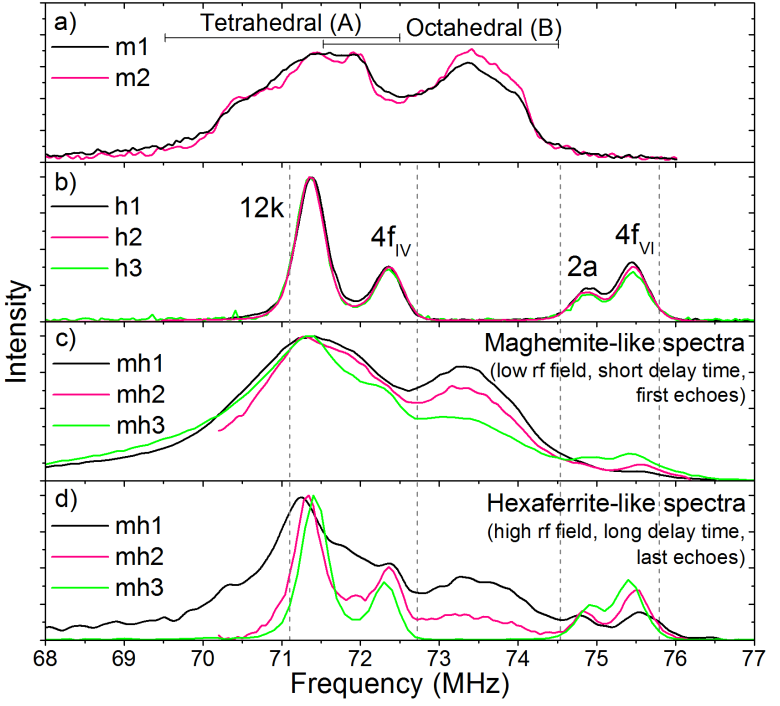

Fig. 1. ${ }^{57} \mathrm{Fe}$ NMR spectra of composite nanoparticle samples recorded in a zero external magnetic field at $4.2 \mathrm{~K}$. Spectra are scaled to maximum of intensity. Assignement of spectral lines to tetrahedral A and octahedral $\mathrm{B}$ sites in maghemite and to $12 \mathrm{k}, 4 \mathrm{f}_{\mathrm{IV}}, 2 \mathrm{a}, 4 \mathrm{f}_{\mathrm{VI}}$ sites in M-type hexaferrite is given. Dashed vertical lines show resonance frequencies in bulk strontium Mhexaferrite.

2a: $\left.74.5390 \mathrm{MHz}, 4 \mathrm{f}_{\mathrm{VI}}: 75.7940 \mathrm{MHz},[15]\right)$ by $0.31-$ $0.33 \mathrm{MHz}$ : lines of $\mathrm{Fe}^{3+}$ sites with "spin up" orientation (12k and 2a) are shifted to lower frequencies while the lines of "spin down" sites $\left(4 \mathrm{f}_{\mathrm{IV}}\right.$ and $\left.4 \mathrm{f}_{\mathrm{VI}}\right)$ shift to higher frequencies. These shifts can be attributed mostly to contribution of demagnetizing fields and the shift values imply $0.22-0.24 \mathrm{~T}$ in magnetic field units (using ${ }^{57} \mathrm{Fe}$ gyromagnetic ratio $1.377 \mathrm{MHz} / \mathrm{T}$ ) which corresponds to ellipsoidal particle shapes of $a / c$ ratio about $0.98-0.89$.

The remaining cases comprise composite samples mh1, $\mathrm{mh} 2$, and mh3. For each sample, a pair of spectra was recorded (Fig. 1c,d) to reflect the differences in optimal excitation and processing conditions of the two expected ferrimagnetic phases. Spectra in Fig. 1c are acquired using low rf field, short delay time and former echoes in the CPMG train while spectra in Fig. 1d are obtained with approximately five times stronger rf field, longer delay time and with processing of later echoes. Example of the dependences of signal intensity on rf field amplitude is given in Fig. 2 and shows also the differences due to delay times and processed echo numbers. Evidently, lineshapes in Fig. 1c bear a resemblance to maghemite spectra and the maghemite-like profile is more pronounced for shorter annealing time. Figure 1d shows that longer annealing results in hexaferrite-like spectral profile and a pure hexaferrite spectrum is seen for sample mh3 while the spectra of $\mathrm{mh} 2$ and $\mathrm{mh} 3$ are rather complex.

A more detailed analysis of the complex spectra of samples mh1 and mh2 in Fig. 1d (hexaferrite-like) and of samples mh1, mh2 and mh3 in Fig. 1c (maghemite-like) showed that they are not simple linear combinations of 


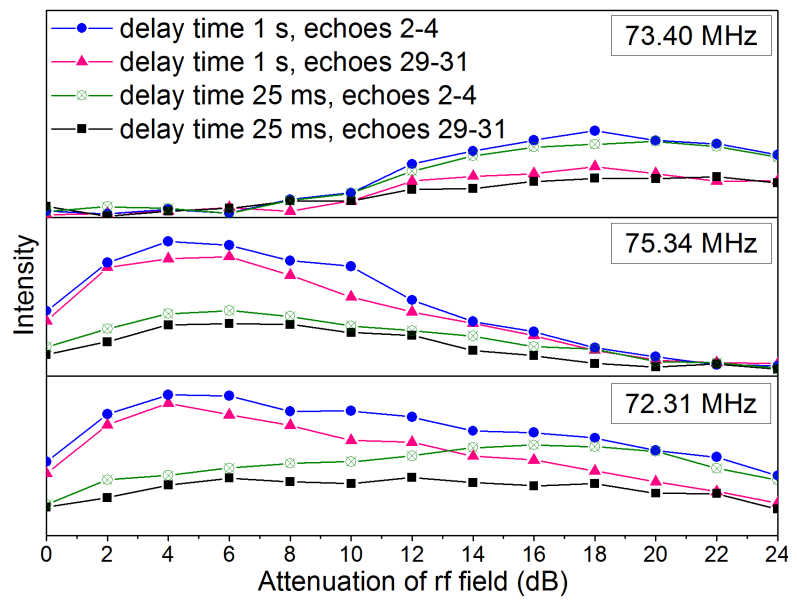

Fig. 2. Dependences of NMR signal intensity on the attenuation of applied rf field for pulse lengths in CPMG sequence $2 / 4 \mu \mathrm{s}$, measured at frequencies $73.40 \mathrm{MHz}$ (maghemite resonance), $75.34 \mathrm{MHz}$ (hexaferrite) and $72.31 \mathrm{MHz}$ (both phases).

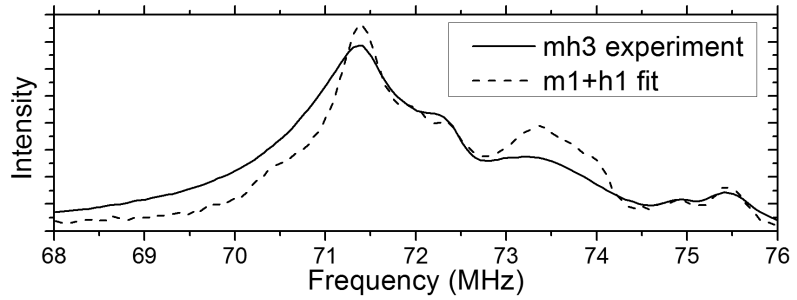

Fig. 3. Decomposition of NMR maghemite-like spectrum of sample mh3, based on linear combination of spectral profiles of maghemite and hexaferrite spectra of samples $\mathrm{m} 1$ and $\mathrm{h} 1$.

maghemite and hexaferrite spectral profiles. In Fig. 3 a decomposition of spectrum of sample mh3 is shown as an example. Spectral shapes observed in these cases may be brought about by an imperfect crystalline structure structural defects, deviations from stoichiometry, stacking faults in hexaferrite or admixture of other hexaferrite building blocks/phases.

\section{Conclusions}

A series of nanocrystalline samples containing ferrimagnetic phases of maghemite and strontium M-type hexagonal ferrite was prepared by sol-gel technique. The ferrite content and particle size significantly increases with increasing annealing temperature, annealing time affects mostly particle size.

The sample series was investigated by ${ }^{57} \mathrm{Fe}$ NMR. ${ }^{57} \mathrm{Fe}$ NMR spectroscopy appeared to be useful in monitoring of maghemite and hexaferrite phases and in detection of coexistence of the two ferrimagnetic phases in composite samples. Proper choice of excitation and processing parameters allowed us (at least partially) to separate signals of maghemite and hexagonal ferrite.

\section{Acknowledgments}

This work was supported by the project No. 716314 of the Grant Agency of the Charles University and by the project SVV-2014-260091. The work is a part of activities of the Charles University Research Center UNCE 204023 "Physics of Condensed Matter and Functional Materials".

\section{References}

[1] E. Pollert, P. Veverka, M. Veverka, O. Kaman, K. Závěta, J. Vasseur, R. Epherre, D. Goglio, E. Duguert, Prog. Solid State Chem. 37, 1 (2009).

[2] X.S. Liu, W. Zhong, B.X. Gu, Y.W. Du, J. Appl. Phys. 92, 1028 (2002).

[3] P. Novák, J. Englich, H. Štěpánková, J. Kohout, H. Lütgemeier, K. Wagner, W. Tolksdorf, Phys. Rev. Lett. 75, 545 (1995).

[4] H. Štěpánková, J. Kohout, P. Novák, J. Englich, E.G. Caspary, H. Lütgemeier, J. Austral. Phys. 51, 437 (1998).

[5] P. Veverka, K. Knížek, E. Pollert, J. Boháček, S. Vasseur, E. Duguet, J. Portier, J. Magn. Magn. Mater. 309, 106 (2007).

[6] P. Veverka, E. Pollert, K. Závěta, S. Vasseur, E. Duguet, Nanotechnology 19, 215705 (2008).

[7] E.A. Turov, M.P. Petrov, Nuclear Magnetic Resonance in Ferro- and Antiferromagnets, Halstead Press, New York 1972.

[8] S.-J. Lee, S. Lee, New J. Phys. 8, 98 (2006).

[9] T. Bastow, A. Trinchi, M. Hill, R. Harris, T.H. Muster, J. Magn. Magn. Mater. 321, 2677 (2009).

[10] J.J. Przewoźnik, T. Tyliszczak, J. Żukrowski, D. Rybicki, Cz. Kapusta, M. Sikora, H. Štěpánková, R.M. Ibarra, D. Serrate, Solid State Phenom. 140, 47 (2008).

[11] P. Křišt’an, V. Chlan, H. Štěpánková, R. Řezníček, K. Kouřil, J. Štěpánek, K. Poláková, V. Procházka, J. Čuda, I. Medř́ík, J. Nanomater. 2013, 179794 (2013).

[12] P. Křištan, V. Chlan, H. Štěpánková, R. Řezníček, P. Görnert, P. Payer, Acta Phys. Pol. A 126, 138 (2014).

[13] H. Štěpánková, K. Kouřil, V. Chlan, P. Görnert, R. Müller, J. Stěpánek, J. Magn. Magn. Mater. 322, 1323 (2010).

[14] H. Štěpánková, J. Englich, P. Novák, D. Sedlák, M. Pfeffer, Hyperfine Interact. 50, 639 (1989).

[15] H. Štěpánková, Ph.D. Thesis, Charles University in Prague, Faculty of Mathematics and Physics, Prague 1994. 